\title{
Prognostic factors for musculoskeletal sickness absence and return to work among welders and metal workers
}

\author{
Alex Burdorf, Bart Naaktgeboren, Wendel Post
}

\begin{abstract}
Objectives-To analyse factors that determine the occurrence of sickness absence due to musculoskeletal problems and the time it takes to return to work.

Methods-A longitudinal study with two year follow up was conducted among 283 male welders and metal workers. The survey started with a standardised interview on the occurrence of musculoskeletal complaints. $61(22 \%)$ workers were lost to follow up. Data on sickness absence among 222 workers during the follow up were collected from absence records and self reports. Regression analysis based on proportional hazards models was applied to identify risk factors for the occurrence and duration of sickness absence due to various musculoskeletal complaints.
\end{abstract}

Results-During the follow up $51 \%$ of the workers attributed at least one period of sickness absence to musculoskeletal complaints which accounted for $44 \%$ of all work days lost. A history of back pain was not associated with sickness absence for back pain, partly because subjects with back pain were more likely to be lost to follow up. Neck or shoulder pain and pain of the upper extremities contributed significantly to neck or shoulder absence (relative risk (RR) 3.35; 95\% confidence interval (95\% CI) 1.73 to 6.47$)$ and to upper extremities absence (RR 2.29; 95\% CI 1.17 to 4.46), respectively. Company and job title were also significant predictors for sickness absence due to these musculoskeletal complaints. Absence with musculoskeletal complaints was not associated with age, height, body mass index, smoking, and duration of employment. Return to work after neck or shoulder absence was worse among metal workers than welders (RR 2.12; 95\% CI 1.08 to 4.17). Return to work after lower extremities absence was strongly influenced by visiting a physician (RR 11.31; 95\% CI 2.94 to 43.46 ) and by musculoskeletal comorbidity (RR 2.81; 95\% CI 1.18 to 6.73).

Conclusions-Complaints of the neck or shoulder and upper extremities in the 12 months before the study were associated with sickness absence for these complaints during the follow up. Workers with absence due to pain from back, neck or shoulder, upper extremities, or lower extremities were at higher risk of subsequent sickness absence in the next year. (Occup Environ Med 1998;55:490-495)
Keywords: musculoskeletal complaints; back pain; sickness absence; return to work

Musculoskeletal disorders have been an important cause of morbidity and disability in many occupational populations during the past few decades. The prodigious volume of musculoskeletal disorders and injuries and their profound economic impact in the workplace have initiated many studies aimed at identifying the essential risk factors for work related musculoskeletal disorders and at establishing sound intervention strategies. ${ }^{12}$ Despite many publications, there seems to have been limited success in the prevention of work related musculoskeletal disorders. ${ }^{34}$ It is difficult to discern whether this lack of progress is due to our limited understanding of the aetiology of musculoskeletal disorders, to selection of inappropriate interventions, or to inadequate implementation of interventions. $^{3}$

For back disorders, the most common musculoskeletal disorder in occupational populations, it has been advocated that prevention should be focused on disability resulting from these problems rather than on preventing onset of pain. ${ }^{56}$ Low back pain is a remarkably common condition affecting most people at some point in life. Fortunately, it is usually a self limiting condition in which recovery without medical treatment occurs in most episodes. ${ }^{7-9}$ Hence, it is arguable that a condition that occurs often and usually remits spontaneously is not worth preventing. ${ }^{510}$ Only a few people with back pain become disabled by it, and medical attention should focus on those subjects with a slow recovery from back pain. ${ }^{11} 12$ Therefore, in considering the problem of musculoskeletal disorders at work, it is important to differentiate between aetiological and prognostic factors, and subsequently identify which factors affect the workers' ability to cope with his musculoskeletal problem at work. ${ }^{13}$

Despite the fact that many articles have been published in recent years on the natural history of musculoskeletal disorders, especially low back pain, the development of temporary disability and recovery are not well documented. $^{5814}$ In the current longitudinal study prognostic factors for sickness absence due to musculoskeletal complaints were evaluated. The aim of the study was to describe the frequency and duration of sickness absence due to musculoskeletal disorders, and to investigate which factors determine the occurrence of sickness absence and the time it takes to return to work. 


\section{Methods}

STUDY POPULATION

The study population consisted of male welders and metal workers of two companies involved in fabrication of large constructions, such as bridges and oilrigs. All welders were involved in welding during most of their daily work. They performed their activities in welding booths as well as on site. About $90 \%$ of the work time was spent welding mild steel, although stainless steel was occasionally used. The group of metal workers consisted of those with various job titles, comprising caulkerburners, fitters, turners, sheet metal workers, plumbers, and grinders. All 312 workers employed in their present job for at least 12 months were invited to participate in the study.

\section{STUDY DESIGN AND DATA COLLECTION}

During 1993-4, study participants were interviewed by the occupational physician at entry into the study. The questionnaire included questions on age, height, weight, smoking history, duration of employment in current and previous jobs, and on musculoskeletal complaints in several body regions. ${ }^{15}$ These questions were derived from the standardised Nordic questionnaire for the analysis of musculoskeletal symptoms. ${ }^{16}$ Musculoskeletal pain was defined as pain which had persisted for at least a few hours during the past 12 months. As the occurrence of neck and shoulder pains were strongly interrelated, the positive answers to these questions were combined. Questions pertaining to musculoskeletal pain in the elbow, wrist, and hand were collapsed into the category pain in the upper extremities and similar questions on pain in the knee, ankle, and foot were grouped into pain in the lower extremities.

During a two year follow up of each subject medical records were retrieved for information on frequency and duration of spells of sickness absence, and symptoms and diagnosis reported to have caused the sickness absence. The register of sickness absence recorded the occurrence and duration of every period of absence. If a worker fell ill, he was obliged to report his absence to the administration office. Subsequently, the worker was sent a short questionnaire with 24 questions on specific symptoms. This self administered questionnaire enabled the worker to report one or more complaints underlying his sickness absence. For the purpose of this study, the causes of sickness absence were categorised into nine groups; back disorder, neck or shoulder disorder, upper extremity disorder, lower extremity disorder, influenza, chronic non-specific lung disorder, stress symptoms, aspecific symptoms, and reasons unknown. When for a particular sickness absence two health complaints were recorded, half of the sick days were attributed to either cause. The following outcomes of sickness absence per worker were collected: prevalence of absence (at least one period of sickness absence during the two year follow up), duration of absence (number of work days with sickness absence), frequency of absence (number of periods of sickness absence), and absence ratio (percentage of work days with sickness absence). In the last three measures workers without absence were excluded from the calculations. To avoid a strong influence of selective participation, respondents were excluded from the study if they had failed to return the sickness absence questionnaire more than once or if their sickness absence with unknown reason exceeded 10 working days.

\section{STATISTICAL ANALYSIS}

The two principal outcomes of the study were time of follow up without sickness absence and duration of sickness absence due to musculoskeletal complaints. Kaplan-Meier curves were produced to describe the proportion of workers without sickness absence relative to time since start of follow up, and the proportion of workers returning to work as a function of duration of sickness absence. Regression analysis based on the proportional hazards model was used to study prognostic factors simultaneously and to adjust for potential confounders. ${ }^{17}$ In the survival analysis on time without sickness absence due to musculoskeletal complaints, right censoring of data was necessary as about $49 \%$ of the workers did not fall sick during the two year follow up period. For these workers, the observed time was less than the (unknown) actual survival time.

Univariate analyses were performed to examine the covariates age, height, weight, body mass index, smoking habits, duration of total employment, duration of employment in the current job, company, job title, comorbidity by other musculoskeletal complaints, and duration and severity of musculoskeletal complaints. Likelihood ratio tests were applied to select the initial variables for inclusion in the multivariate analyses, with, as an inclusion criterion, a level of significance of 0.10 . The multivariate proportional hazards models included all variables that contributed significantly to the final model (Wald statistics, criterion of $p \leqslant 0.05$ ). Age was included in each model, regardless of its level of significance. For each factor the hazard ratio and $95 \%$ confidence interval $(95 \% \mathrm{CI})$ were calculated. The hazard ratio is interpreted as the relative risk (RR) at any time during the follow up. All statistical analyses were performed with SAS software, with the procedure PROC PHREG for the survival analysis.

\section{Results}

RESPONSE

The initial response to participate in the study was $91 \%$ (283 respondents). During the two year follow up 23 respondents changed job or retired, and 38 respondents were not included in the final analysis due to incomplete data on causes of sickness absence. A non-response analysis showed that in the baseline survey the subjects lost during the follow up $(n=61)$ reported significantly more back pain (odds ratio (OR) $2.01,95 \%$ CI 1.09 to 3.72 ) than those who completed the study. No differences were found for age, smoking, job title, company, and prevalence of complaints on the neck or shoulder, upper extremities, and lower extremities. 
Table 1 Individual characteristics and working experience of welders and metal workers at the start of the longitudinal study

\begin{tabular}{lrrrrr}
\hline & $\begin{array}{c}\text { Welders } \\
(n=97)\end{array}$ & & \multicolumn{2}{c}{$\begin{array}{l}\text { Metal workers } \\
(n=125)\end{array}$} \\
\cline { 2 - 3 } \cline { 6 - 6 } & Mean & $S D$ & & Mean & $S D$ \\
\hline Individual characteristics: & & & & \\
$\quad$ Age (y) & 41.5 & 10.3 & & 39.8 & 9.6 \\
$\quad$ Height (cm) & 177.6 & 7.6 & & 177.9 & 7.0 \\
$\quad$ Weight (kg) & 79.2 & 11.4 & & 79.3 & 10.6 \\
Work history: & & & & \\
$\quad$ Employment in current & & & & \\
$\quad$ company (y) & 13.8 & 7.9 & & 13.3 & 7.8 \\
$\quad$ Total working experience (y) & 22.9 & 11.4 & & 22.0 & 10.6 \\
\hline
\end{tabular}

Table 2 Prevalence of musculoskeletal complaints in the past 12 months before the start of the study among welders and metal workers

\begin{tabular}{llllll}
\hline & \multicolumn{2}{l}{$\begin{array}{l}\text { Welders } \\
(n=97)\end{array}$} & & \multicolumn{2}{c}{$\begin{array}{l}\text { Metal workers } \\
(n=125)\end{array}$} \\
\cline { 2 - 3 } \cline { 6 - 6 } Pain & $n$ & $\%$ & & $n$ & $\%$ \\
\hline Back & 38 & 39 & & 51 & 41 \\
Neck & 24 & 25 & & 25 & 20 \\
Shoulder & 26 & 27 & & 27 & 22 \\
Elbow & 11 & 12 & & 17 & 14 \\
Wrist & 14 & 15 & & 11 & 9 \\
Knee & 31 & 33 & & 41 & 33 \\
Ankle or foot & 14 & 15 & & 18 & 14 \\
\hline
\end{tabular}

BASELINE CHARACTERISTICS

Table 1 shows the basic characteristics of the 222 workers in the study population. The population consisted predominantly of middle aged men, although age ranged from 19 to 59 years. Welders and metal workers did not differ for individual characteristics and distributions of duration of employment in current and previous jobs. About $82 \%$ had had previous jobs and most of the previous positions held were comparable with the current occupation. In both groups current smokers (43\%) had smoked for about 23 years and ex-smokers (25\%) stopped smoking, on average, almost 10 years before the study.

The prevalence of musculoskeletal complaints in the 12 months before the study was highest for back pain (40\%) and knee pain (33\%) in both groups (table 2). The prevalences of neck and shoulder pain showed an overlap of $36 \%$, resulting in a combined prevalence of $34 \%$

Table 3 Sickness absence due to musculoskeletal complaints during the two year follow up among 222 welders and metal workers

\begin{tabular}{llrl}
\hline Variables of sickness absence & $n$ & Mean & Range \\
\hline Back: & 50 & & \\
$\quad$ Prevalence (workers (n)) & 67 & 1.3 & $1-4$ \\
Frequency (absence periods (n)) & 67 & 14.5 & $1-169$ \\
Duration (work days of absence) & 50 & 4.4 & $0.2-38.4$ \\
$\quad$ Ratio (work days with sickness absence (\%)) & & & \\
Neck or shoulder: & 38 & 1.3 & $1-3$ \\
$\quad$ Prevalence (workers (n)) & 49 & 14.6 & $2-176$ \\
Frequency (absence periods (n)) & 49 & 4.3 & $0.5-40.0$ \\
Duration (work days of absence) & 38 & & \\
Ratio (work days with sickness absence (\%)) & & & \\
Upper extremities: & 40 & 1.3 & $1-3$ \\
$\quad$ Prevelance (workers (n)) & 52 & 22.7 & $1-176$ \\
Frequency (absence periods (n)) & 52 & 6.7 & $0.2-40.0$ \\
Duration (work days of absence) & 40 & & \\
Ratio (work days with sickness absence (\%)) & 51 & & \\
Lower extremities: & 82 & 1.6 & $1-5$ \\
Prevalence (workers (n)) & 82 & 20.0 & $2-260$ \\
Frequency (absence periods (n)) & 51 & 7.3 & $0.4-59.1$ \\
$\quad$ Duration (work days of absence) & &
\end{tabular}

$(n=75)$. Welders had more neck or shoulder complaints than metal workers $(40 \%$ v $29 \%)$ but this difference did not quite reach conventional levels for significance $\left(\chi^{2}\right.$ test, $\left.\mathrm{p}=0.07\right)$. The prevalence of upper extremity pain was $21 \%(n=46)$ with pain in the elbow and in the wrist contributing almost equally. The occurrence of complaints of the lower extremities $(40 \%)$ was largely pain in the knee. Most workers reported more than one complaint about musculoskeletal pain in a particular body region.

\section{SICKNESS ABSENCE}

Among the 222 people with sufficient data during the study, $29(13 \%)$ did not take any sick leave at all. During the follow up over two years, $193(87 \%)$ workers were absent from work due to sickness for one or more periods, resulting in a total of 787 sickness absence periods covering 8306 days. In 290 spells of absence, workers reported more than one complaint associated with their sickness absence. Comorbidity was highly prevalent for influenza and chronic non-specific respiratory complaints (about $50 \%$ ) and for influenza and aspecific symptoms (about 67\%) which primarily comprised cold, headache, and sore throat. For musculoskeletal complaints, comorbidity was reported for the back and the neck or shoulder in 14 absence periods, and for the neck or shoulder and arm in eight periods of absence. During the two year follow up the sickness absence ratio in the total group was $8.5 \%$ with musculoskeletal complaints accounting for $44 \%$ of the days lost, influenza $19 \%$, stress symptoms $8 \%$, other causes $26 \%$, and unknown causes $3 \%$.

Table 3 shows the prevalence, frequency, duration, and ratio of sickness absence of musculoskeletal origin. During the two year follow up the proportion of workers that experienced at least one period of sickness absence as a result of back pain was $23 \%$, neck or shoulder pain $17 \%$, upper extremities $18 \%$, and lower extremities $23 \%$. During the follow up, about $51 \%$ of the workers attributed at least one period of sickness absence to musculoskeletal complaints. Figure 1 shows the distribution of time at work before a first sickness absence due to these complaints. No differences were found between the prevalences in the first year and those in the second year of follow up. As can be seen from the frequencies

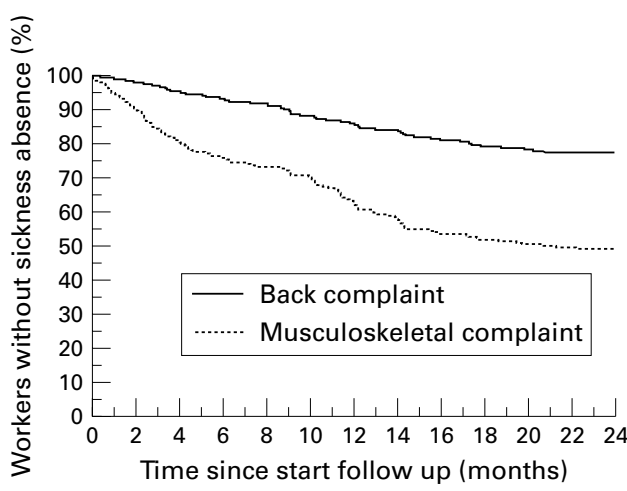

Figure 1 Survival time to a first period of sickness absence due to back pain and to musculoskeletal complaints over the two years of follow up. 


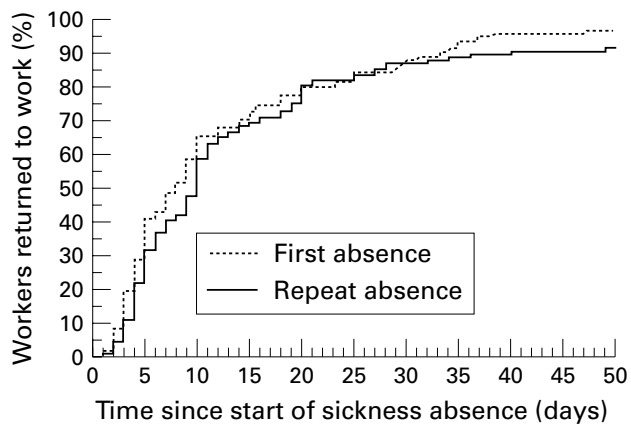

Figure 2 Cumulative rate of return to work after sickness absence due to musculoskeletal complaints.

of sickness absence in table 3, several workers were absent more than once for the same complaint. The probability of a recurrent sickness absence within one year was significantly higher than the probability of a first sickness absence within one year. For back pain a one year recurrence rate of $22 \%$ was found, for the neck or shoulder $21 \%$, for the upper extremities $20 \%$, and for the lower extremities $25 \%$.

A few spells of sickness absence involved a direct blow or a fall, slip, or trip at work. Sickness absence was attributed to accidents in four $(6 \%)$ cases of back pain, five $(10 \%)$ neck or shoulder complaints, $12(23 \%)$ disorders of the upper extremities, and $17(21 \%)$ disorders of the lower extremities.

The distribution of the duration of sickness absence did not differ among the specific musculoskeletal disorders. Figure 2 shows the return to work for workers who lost any time off work because of a first spell of musculoskeletal complaints. Almost no difference was found in rates of return to work between first periods and subsequent periods of sickness absence due to musculoskeletal disorders. Most workers (60\%) returned to work within 10 work days (about two weeks). However, a few $(21 \%)$ were off work after 20 days (one month), and 3\% were still off work after 110 days (about six months).
PROGNOSTIC FACTORS

Table 4 presents the factors associated with the occurrence of sickness absence due to musculoskeletal complaints during the two year follow up. The presence of musculoskeletal pain in the 12 months before the study was a significant predictor for sickness absence due to neck or shoulder pain (RR 3.35; 95\% CI 1.73 to 6.47 ) and to pain in the upper extremities (RR 2.29; $95 \%$ CI 1.17 to 4.46$)$. However, back complaints (RR $0.94 ; 95 \%$ CI 0.53 to 1.66 ) and complaints of the lower extremities (RR 1.40; $95 \%$ CI 0.81 to 2.43 ) were not associated with an increased probability of sickness absence. For the prognostic value of severe musculoskeletal complaints, pain in the lower extremities that caused workers to visit their general practitioner significantly contributed to the prediction of sickness absence due to trouble with the lower extremities. In none of the multivariate models was age a significant risk factor. Individual characteristics - such as height, body mass index, smoking, and duration of employmentwere also not associated with the probability of taking sick leave.

Table 5 shows the prognostic factors for return to work after a period of sickness absence. For neck or shoulder sickness absence metal workers had a significantly decreased chance of returning to work quickly compared with welders (RR 2.12; 95\% CI 1.08 to 4.17). Workers with pain in the lower extremities stayed off work significantly longer when they experienced other musculoskeletal complaints as well (RR $2.81 ; 95 \%$ CI 1.18 to 6.73 ) and when they sought medical care for their complaints (RR $11.31 ; 95 \%$ CI 2.94 to 43.46 ). Individual characteristics and work history were not associated with the probability of return to work.

\section{Discussion}

Data on the natural course of musculoskeletal pain and subsequent sickness absence are sparse. ${ }^{418}$ This study among welders and

Table 4 Multivariate hazard RRs (95\% CIs) of prognostic factors for sickness absence due to musculoskeletal disorders

\begin{tabular}{|c|c|c|c|c|c|}
\hline Cause of sickness absence & Factor & Subjects & $R R$ & $(95 \% C I)$ & $p$ Value \\
\hline \multirow[t]{3}{*}{ Back } & Age (y): & & & & \\
\hline & $\leqslant 40$ & 109 & 1.00 & & \\
\hline & $>40$ & 113 & 1.42 & $(0.81$ to 2.49$)$ & 0.22 \\
\hline \multirow[t]{8}{*}{ Neck or shoulder } & Age (y): & & & & \\
\hline & $\leqslant 40$ & 109 & 1.00 & & \\
\hline & $>40$ & 113 & 0.83 & $(0.44$ to 1.57$)$ & 0.83 \\
\hline & Company A $v$ & 137 & 1.00 & & \\
\hline & Company B & 85 & 0.46 & $(0.21$ to 1.00$)$ & 0.05 \\
\hline & Neck or shoulder complaint before study: & & & & \\
\hline & No & 147 & 1.00 & & \\
\hline & Yes & 75 & 3.35 & (1.73 to 6.47$)$ & 0.001 \\
\hline \multirow[t]{8}{*}{ Upper extremities } & Age (y): & & & & \\
\hline & $\leqslant 40$ & 109 & 1.00 & & \\
\hline & $>40$ & 113 & 1.25 & $(0.67$ to 2.34$)$ & 0.49 \\
\hline & Welders $v$ & 97 & 1.00 & & \\
\hline & metal workers & 125 & 2.21 & (1.11 to 4.41$)$ & 0.02 \\
\hline & Upper extremity complaint before study: & & & & \\
\hline & No & 176 & 1.00 & & \\
\hline & Yes & 46 & 2.29 & (1.17 to 4.46$)$ & 0.02 \\
\hline \multirow[t]{6}{*}{ Lower extremities } & Age (y): & & & & \\
\hline & $\leqslant 40$ & 109 & 1.00 & & \\
\hline & $>40$ & 113 & 0.73 & $(0.42$ to 1.27$)$ & 0.26 \\
\hline & $\begin{array}{l}\text { Visit to physician with lower extremity pain } \\
\text { in } 12 \text { months before the study: }\end{array}$ & & & & \\
\hline & No & 217 & 1.00 & & \\
\hline & Yes & 5 & 3.23 & (1.00 to 10.5$)$ & 0.05 \\
\hline
\end{tabular}


Table 5 Multivariate hazard RRs (95\% CIs) of prognostic factors for return to work after sickness absence due to musculoskeletal disorders

\begin{tabular}{|c|c|c|c|c|c|}
\hline $\begin{array}{l}\text { Cause of sickness } \\
\text { absence }\end{array}$ & Factor & Subjects & $R R$ & $(95 \% C I)$ & $p$ Value \\
\hline \multirow[t]{3}{*}{ Back } & Age (y): & & & & \\
\hline & $\leqslant 40$ & 21 & 1.00 & & \\
\hline & $>40$ & 29 & 1.54 & (0.87 to 2.74$)$ & 0.14 \\
\hline \multirow[t]{5}{*}{ Neck/shoulder } & Age $(y)$ : & & & & \\
\hline & $\leqslant 40$ & 19 & 1.00 & & \\
\hline & $>40$ & 19 & 1.32 & (0.70 to 2.49$)$ & 0.40 \\
\hline & Welders $v$ & 18 & 1.00 & & \\
\hline & Metal workers & 20 & 2.12 & (1.08 to 4.17$)$ & 0.03 \\
\hline \multirow[t]{3}{*}{ Upper extremities } & Age $(y)$ : & & & & \\
\hline & $\leqslant 40$ & 19 & 1.00 & & \\
\hline & $>40$ & 21 & 1.21 & (0.64 to 2.32$)$ & 0.56 \\
\hline \multirow[t]{9}{*}{ Lower extremities } & Age $(y)$ : & & & & \\
\hline & $\leqslant 40$ & 28 & 1.00 & & \\
\hline & $>40$ & 23 & 0.85 & $(0.47$ to 1.53$)$ & 0.59 \\
\hline & $\begin{array}{l}\text { Visit to physician with lower extremity pain in } 12 \\
\text { months before the study: }\end{array}$ & & & & \\
\hline & No & 48 & 1.00 & & \\
\hline & Yes & 3 & 11.31 & (2.94 to 43.46$)$ & 0.001 \\
\hline & Comorbidity by other musculoskeletal complaints: & & & & \\
\hline & No & 44 & 1.00 & & \\
\hline & Yes & 7 & 2.81 & (1.18 to 6.73$)$ & 0.02 \\
\hline
\end{tabular}

metal workers showed that over a two year period about $50 \%$ of the workers attributed at least one episode of sickness absence to musculoskeletal complaints. The profound impact of musculoskeletal disorders on the workforce was also illustrated by the finding that these disorders accounted for $44 \%$ of all working days lost during the follow up. The one year rate of absence due to back pain was $11 \%$ and for the neck or shoulder, lower extremities, and upper extremities very similar rates of absence were found. The one year rate of absence for back pain among the welders and metal workers was higher than the reported one year rates of $6 \%$ among Swedish workers ${ }^{19}$ and $7 \%$ in British nurses. ${ }^{20}$ However, these studies were based on self reports rather than sickness absence registries and some underreporting may have occurred. ${ }^{15}$

The prevalences of particular musculoskeletal complaints in the 12 months preceding the baseline survey were within the range of reported prevalences in occupational groups of blue collar workers. ${ }^{2122}$ The prevalences were three to four times higher than the subsequent rates of sickness absence in the next year. This finding suggests that a substantial proportion of workers continued their regular work while experiencing an episode of musculoskeletal pain..$^{12} 23$ The one year recurrence rates for particular musculoskeletal sickness absences were about twice the one year period prevalences, indicating that workers with previous temporary disability from musculoskeletal problems are at higher risk of subsequent sickness absence. The observed twofold risk is subject to some uncertainty as the exact risk of a recurrent period of absence could not be assessed directly in this study. The period prevalence of a period of absence in the first year of follow up combines incidence (a first absence period among workers without a history of absence for musculoskeletal complaints) and recurrence (an absence period as a recurrence from episodes before the study period). However, the observed increased risks for recurrent periods of absence are consistent with reports on one year recurrence rates of absence for back pain of $20 \%$ among compensated workers with occupational back injuries in Quebec ${ }^{24}$ and 31\% among Swedish automobile workers with back injury. ${ }^{25}$

In this study no differences were found among the distributions of duration of sickness absence for particular musculoskeletal complaints. On average, about $60 \%$ of the workers returned to work within two weeks (10 work days), and about $80 \%$ returned to work within four weeks (fig 2). These figures comply well with published information on the duration of lost time claims due to back injury in the Ontario worker's compensation system. ${ }^{18}$ The distributions of return to work after a first period of sickness absence and after a repeat period of sickness absence were similar. Although the information on duration of recurrent episodes of sickness absence was based on only 69 events, this finding does not support the hypothesis that subjects off work for recurrent periods have passed through earlier stages of disability with less lost time. ${ }^{5}$ Among welders and metal workers, subjects with musculoskeletal sickness absence were at increased risk for a recurrent episode but this second episode did not delay return to work. In this study it was not possible to distinguish between complete recovery from a musculoskeletal complaint and return to work as the presence of residual musculoskeletal pain when resuming work was not ascertained. Some authors have pointed out that recovery and return to work are outcomes that should be differentiated. ${ }^{8}$ In this study return to work and recovery may have been similar as workers did not experience any cut in their regular wages within the first few weeks of sickness absence.

In the regression analysis several factors were evaluated as to their influence on the probability of occurrence of sickness absence due to musculoskeletal disorders. Individual characteristics, such as age, height, weight, smoking, and duration of employment were not predictive for musculoskeletal pain leading to absence from work. Previous complaints of the neck or shoulder, upper extremities, and lower extremities (when medical care was sought) were 
significant predictors for future sickness absence due to these complaints. Surprisingly, the occurrence of back pain in the 12 months before the study was not associated with absence for back pain. This contrasts with the common finding that a history of (chronic) back pain is a strong risk factor for recurrent back pain and sickness absence. ${ }^{5}{ }^{17-20}$ A possible explanation for this contradictory result might be that subjects whose back pain followed a more chronic unremitting course were overrepresented among those lost to follow up. The non-response analysis showed that subjects who dropped out of the study during the follow up reported significantly more back pain than those who completed the study. No selective participation with regard to other musculoskeletal complaints was found.

Company and job title were predictors for sickness absence for pain of the neck or shoulders and for the upper extremities, respectively. This may reflect differences in work activities and working conditions between companies and jobs. Other prognostic factors described in the scientific literature-such as poor working relations, ${ }^{26}$ management policy, ${ }^{27}$ and worker's avoidance behaviour ${ }^{28}$ - are less likely to explain these results as these risk factors would have entertained a similar systematic effect on all four categories of musculoskeletal complaints.

The available information on return to work after an episode of musculoskeletal sickness absence is based on small numbers. Hence, the statistical analysis provided limited insight into possible prognostic factors for return to work. Moreover, the study population of welders and metal workers may lack sufficient contrast in exposure and health status to ascertain their impact on return to work. It should be borne in mind that the current study included all cases of musculoskeletal absence, irrespectively of the duration of absence and whether the subjects off work sought medical care. Within the framework of the study is was not feasible to conduct a clinical evaluation of every case at the onset of his absence. Hence, the results in this longitudinal study among workers may differ from inception cohort studies based on groups of patients enrolled in general practice or compensation systems shortly after the onset of symptoms. ${ }^{81114}$ Studies on patients with back pain have pointed at several clinical variables of the complaint as predictors for delayed work resumption ${ }^{81011} 14$ and to effect modifiers such as mental health, poor job satisfaction, and pursuit of compensation. ${ }^{29}$

This longitudinal study has several limitations, most of them related to the inability to perform clinical assessments of the complaints underlying musculoskeletal sickness absence. However, the results showed that a history of complaints of the neck or shoulder and upper extremities in the 12 months before the study was associated with subsequent sickness absence for these complaints during the follow up. Also, workers with absence due to pain from the back, neck or shoulders, upper extremities, or lower extremities were at higher risk for subsequent sickness absence in the next year. It is important to study temporal associations between the occurrence of musculoskeletal complaints and subsequent disability. In this respect, health complaints, sickness absence, and return to work should be studied simultaneously in the same occupational populations.

1 Hagberg M, Silverstein B, Wells R, et al. Work related musculoskeletal disorders (WMSDs): a reference book for prevention. London: Taylor and Francis, 1995.

2 Zwerling C, Daltroy LH, Fine LJ, et al. Design and conduct of occupational injury intervention studies: a review of evaluation strategies. Am f Ind Med 1997;32:164-79.

3 Courtney TK, Burdorf A, Sorock GS, et al. Methodological challenges to the study of occupational injury-an international epidemiology workshop. Am f Ind Med 1997; 32:103-5.

4 Riihimäki H. Hands up or back to work-future challenges in epidemiologic research on musculoskeletal diseases. in epidemiologic research on musculoskel.

5 Frank JW, Brooker AS, DeMaio SE, et al. Disability resulting from occupational low back pain. Part II: What do we know about secondary prevention? A review of the scientific evidence on prevention after disability begins. Spine 1996;21:2918-29.

6 Hadler NM. Regional back pain. N Engl f Med 1986;315: 1090-2.

7 Burton AK, Tillotson KM, Symonds TL, Burke C, Mathewson T. Occupational risk factors for the first-onset and subsequent course of low back trouble. Spine 1996;21: and subseque

8 Coste J, Delecoeuillerie G, Cohen de Lara A, et al. Clinical course and prognostic factors in acute low-back pain: an
inception cohort study in primary care practice. $B M \mathcal{F}$ inception cohort

9 Waddell G. Epidemiology review: the epidemiology and cost of back pain. London: Her Majesty's Stationary Office, 1994.

10 Hazard RG, Haugh LD, Reid S, et al. Early prediction of chronic disability after occupational low back injury. Spine 1996;21:945-51.

11 Reid S, Haugh LD, Hazard RG, et al. Occupational low back pain: recovery curves and factors associated with disability. F Occup Rehab 1997;7:1-14.

12 Von Korff M. Studying the natural history of low back pain. Spine 1994;19:2041S-6S

13 Burdorf A, Rossignol M, Fathallah F, et al. Challenges in assessing risk factors in epidemiologic studies on back disassessing risk factors in epidemiologic stud
orders. Am f Ind Med 1997;32:142-52.

14 Infante-Rivard C, Lortie M. Prognostic factors for return to work after a first compensated episode of back pain. Occup Environ Med 1996;53:488-94.

15 Burdorf A, Post W, Bruggeling T. Reliability of a questionnaire on sickness absence with specific attention to absence due to back pain and respiratory complaints. Occup Environ Med 1996;53:58-62.

16 Kuorinka I, Jonsson B, Kilbom A, et al. Standarised Nordic questionnaire for the analysis of musculoskeletal symptoms. Appl Ergonom 1987;18:233-7.

17 Cox DR, Oakes D, Analysis of survival data. London: Chapman and Hall, 1984.

18 Frank JW, Kerr MS, Brooker AS, et al. Disability resulting from occupational low back pain. Part I: what do we know about primary prevention ? A review of the scientific evidence on prevention before disability begins. Spine 1996;21:2908-17.

19 Biering-Sørensen F. A prospective study of low-back pain in a general population. III Medical service-work consequences. Scand F Rehabil Med 1983;15:89-96.

20 Smedley J, Egger P, Cooper C, et al. Prospective cohort study of predictors of incident low back pain in nurses. $B M \mathcal{F}$ 1997;314:1225-8.

21 Burdorf A, Van Riel M, Brand T. Physical load as risk factor for musculoskeletal complaints among tank terminal workers. Am Ind Hyg Assoc F 1997;58:489-97.

22 Skovron ML. Epidemiology of low back pain. Baillières Clin Rheumatol 1992;6:559-73.

23 Rossignol M, Lortie M, Ledoux E. Comparison of spinal health indicators in predicting spinal status in a 1-year longitudinal study. Spine 1993;18:54-60.

24 Abenhaim L, Suissa S, Rossignol M. Risk of recurrence of occupational back pain over three years follow up. Br f Ind Med 1988;45:829-33.

25 Bergquist-Ullman M, Larsson U. Acute low back pain in industry: a controlled prospective study with special reference to therapy and vocational factors. Acta Orthop Scand 1977; 170(suppl): 1-117.

26 Cats-Baril WL, Frymoyer JW. Identifying patients at risk of becoming disabled because of low-back pain: the Vermont Rehabilitation Engineering Center predictive model. Spine 1991:16:605-7.

27 Hunt HA, Habeck RV. The Michigan disability prevention study. Research highlights. Kalamazoo, MI: Upjohn Institute for Employment Research, 1993.

28 Waddell G, Newton M, Henderson I, et al. A fear-avoidance beliefs questionnaire (FABO) and the role of fearavoidance beliefs in chronic low-back pain and disability. Pain 1993;52:157-68.
Paidance beliefs in chro

29 Greenough CG, Fraser RD. Assessment of outcome in patients with low-back pain. Spine 1992;17:36-41. 